Research Article

\title{
Determination of the Ultimate Underground Mining Depth considering the Effect of Granular Rock and the Range of Surface Caving
}

\author{
Rongxing He $\mathbb{I D}^{1},{ }^{1}$ Jing Zhang ${ }^{\mathbb{D}},{ }^{1}$ Yang Liu ${ }^{D},{ }^{2}$ Delin Song ${ }^{(D},{ }^{2}$ and Fengyu Ren ${ }^{1}{ }^{1}$ \\ ${ }^{1}$ School of Resources and Civil Engineering, Northeastern University, Shenyang 110819, China \\ ${ }^{2}$ School of Mining and Coal, Inner Mongolia University of Science \& Technology, Baotou 014010, China \\ Correspondence should be addressed to Jing Zhang; yuanzhongni33@163.com
}

Received 13 January 2021; Revised 8 February 2021; Accepted 21 February 2021; Published 6 March 2021

Academic Editor: Rossana Dimitri

Copyright (C) 2021 Rongxing He et al. This is an open access article distributed under the Creative Commons Attribution License, which permits unrestricted use, distribution, and reproduction in any medium, provided the original work is properly cited.

Continuous mining of metal deposits leads the overlying strata to move, deform, and collapse, which is particularly obvious when open-pit mining and underground mining are adjacent. Once the mining depth of the adjacent open-pit lags severely behind the underground, the ultimate underground mining depth needs to be studied before the surface deformation extends to the open-pit mining area. The numerical simulation and the mechanical model are applied to research the ultimate underground mining depth of the southeast mining area in the Gongchangling Iron mine. In the numerical simulation, the effect of granular rock is considered and the granular rock in the collapse pit is simplified as the degraded rock mass. The ultimate underground mining depth can be obtained by the values of the indicators of surface movement and deformation. In the mechanical model, the modified mechanical model for the progressive hanging wall caving is established based on Hoke's conclusion, which considers the lateral pressure of the granular rock. Using the limiting equilibrium analysis, the relationship of the ultimate underground mining depth and the range of surface caving can be derived. The results show that the ultimate underground mining depth obtained by the numerical simulation is greater than the theoretical calculation of the modified mechanical model. The reason for this difference may be related to the assumption of the granular rock in the numerical simulation, which increases the resistance of granular rock to the deformation of rock mass. Therefore, the ultimate underground mining depth obtained by the theoretical calculation is suggested. Meanwhile, the surface displacement monitoring is implemented to verify the reasonability of the ultimate underground mining depth. Monitoring results show that the indicators of surface deformation are below the critical value of dangerous movement when the underground is mined to the ultimate mining depth. The practice proves that the determination of the ultimate underground mining depth in this work can ensure the safety of the open-pit and underground synergetic mining.

\section{Introduction}

The overlying rock mass appears to move and destroy caused by the underground mining method, such as the room and pillar mining method $[1,2]$ and the caving mining method $[3,4]$. Gradually, this deformation expands upward to the surface with the development of new cracks and the expansion of primary cracks [5]. The mine area for underground mining may be forced to be closed when the surface strata movement seriously threatens the safety of surface structures, such as roads, bridges, and open pits. Therefore, it is necessary to study the ultimate underground mining depth to ensure the safety of surface structures and prolong the service life of underground mining.

Generally, the range of the surface strata movement increases with the underground mining depth. In other words, the range of the surface strata movement is the key for the study on the ultimate underground mining depth. The mechanisms of strata movement induced by coal mining are extensively studied and lots of achievements have been made, such as the theory of voussoir beams [6], the theory of transferring rock beams [7], the vertical zoning model $[8,9]$, 
the horizontal zoning model $[10,11]$, and the theory of key strata [12-14]. The strata movement of metal mine is studied later than coal mine, and it is more complicated, because there are the following four aspects of differences: the orebody geological conditions, the ratio of the mining depth and the height of goaf, the mining methods and the in-situ stresses $[15,16]$. Brown [17] suggested that the cave propagate vertically to the surface when the ore-body mined by the block caving method is vertical with a well-defined cutoff between it and the surrounding country rock, except for inclined surface slopes forming in weak or weathered surface layers. Hoek [18] studied the progressive collapse of a hanging wall in the Gangesborg Mine using the limiting equilibrium analysis and proposed that the rock mass in the hanging wall can be toppled because a major set of persistent discontinuities dips steeply in a similar direction to the ore body. Subsequently, Brown and Ferguson [19] extended Hoek's analysis to consider a sloping ground surface and groundwater pressure in the tension crack and the shear plane. However, the effect of granular rock [20-23] was neglected to control the surface strata movement.

Some scholars applied the monitoring method to study the surface strata movement. Taking the Chengchao iron mine in China as an example, Zhu [24] summarized the development process of the collapse in the mine and proposed that the surface deformation and failure forms of the mine are dominated by tipping-type fracture; $\mathrm{Xi}$ [25] analyzed the monitoring data of GPS and suggested that the surface deformation of the mine is mainly the ladder deformation towards the goaf; and Cheng $[26,27]$ analyzed the data of the monitoring points displacement and fracture location and divided the surface deformation of the mine into four zones, namely, deformation accumulation zone, fracture generation zone, fracture expansion zone, and fracture closure zone. Based on the monitoring results for nearly 11 years in the Chengchao iron mine, Chen [28] proposed that the monitoring points around the goaf have obvious deformation acceleration before the surface collapse again and the surface deformation is related to the amount and duration of rainfall. Monitoring data can objectively reflect the laws of the strata movement in the mining process. However, the monitoring method is more timeconsuming and of high cost, which cannot be directly used to determine the ultimate underground mining depth. In addition, the numerical method is developed rapidly with the progress of science and technology, which provides a variety of ways for studying the whole process of strata movement induced by underground mining. The numerical simulation software, such as FLAC [29], UDEC [30, 31], PFC [32], DDA [33], ELFEN [34], and RFPA [35], is developed and applied to model the mining-induced subsidence. Numerical modeling is less time-consuming and can visual observation of the deformation and failure of the deep surrounding rock. What most important is that it can predict the strata movement caused by mining and optimize the layout and sequence of mining.

In the following sections, the numerical simulation software FLAC ${ }^{3 \mathrm{D}}$ and the mechanical model for progressive hanging wall caving were applied to determine the ultimate underground mining depth with the southeast mining area in the Gongchangling Iron Mine as the engineering background. The research methods in this work considered the effect of granular rock and the range of surface caving. The ultimate underground mining depth in this work was used to avoid the surface deformation extending to the open-pit mining area, which can ensure the implementation of the open-pit and underground synergetic mining in the Gongchangling Iron Mine. Meanwhile, the surface displacement monitoring was implemented to verify the reasonability of the ultimate underground mining depth.

\section{Engineering Background}

The Gongchangling Iron Mine is located in Liaoyang city, Liaoning province, China. The layered ore body is a sedimentary metamorphic deposit, and the ore body strike is $\mathrm{N} 50^{\circ}$ to $\mathrm{W} 75^{\circ}$. The mine is divided into three mining areas in the direction of the ore body, including the southeast mining area, central mining area, and northwest mining area. The southeast mining area is located between exploration line $\# 19$ and exploration line \#30 and includes two parallel ore bodies. In this mining area, the thickness is $10 \mathrm{~m}$ to $20 \mathrm{~m}$, the average thickness is $15 \mathrm{~m}$, and the angle is $65^{\circ}$ to $85^{\circ}$. The upper iron belts (as shown in Figure 1(a)) are hematite with an average grade of $22.6 \%$. With the improvement of the technology of hematite dressing and the market demand increasing, the upper iron belts are mined recently by open-pit mining. The steps of the open-pit mining are $448 \mathrm{~m}$ to $388 \mathrm{~m}$. The lower iron belt (as shown in Figure 1(a)) is magnetite with an average grade of $33.8 \%$, which is mined by underground mining. The movement angle of the lower iron belt is $65^{\circ}$. The mining method of the lower iron belt has been changed from the shallow-hole shrinkage mining method to the sublevel caving method. The designed mining ultimate level of the shallow-hole shrinkage mining is $150 \mathrm{~m}$. The designed sublevel height of the sublevel caving is $20 \mathrm{~m}$. However, the collapse pit (as shown in Figure 1) appears on the surface when the underground mining level reaches $190 \mathrm{~m}$. As shown in Figure 1(a), the horizontal distance between the upper iron belts and the lower iron belt is $150 \mathrm{~m}$ to $200 \mathrm{~m}$, the height difference of open-pit mining and underground mining is about $300 \mathrm{~m}$. In addition, the distance between the boundary of the current open-pit boundary and the collapse pit is $120 \mathrm{~m}$. In a word, the open-pit mining is located in the moving zone formed by the underground mining, which seriously threatens the production safety of the open-pit mining.

Assuming that the underground mining is terminated to ensure the safety of the open-pit mining, the economic benefits of the Gongchangling Iron Mine can be greatly reduced. Therefore, the method of open-pit and underground synergetic mining is studied to ensure the safety of the open-pit mining and the normal capacity connection. The point is to obtain the ultimate underground mining depth before the collapse zone or fractured zone extends to the open-pit mining area. 


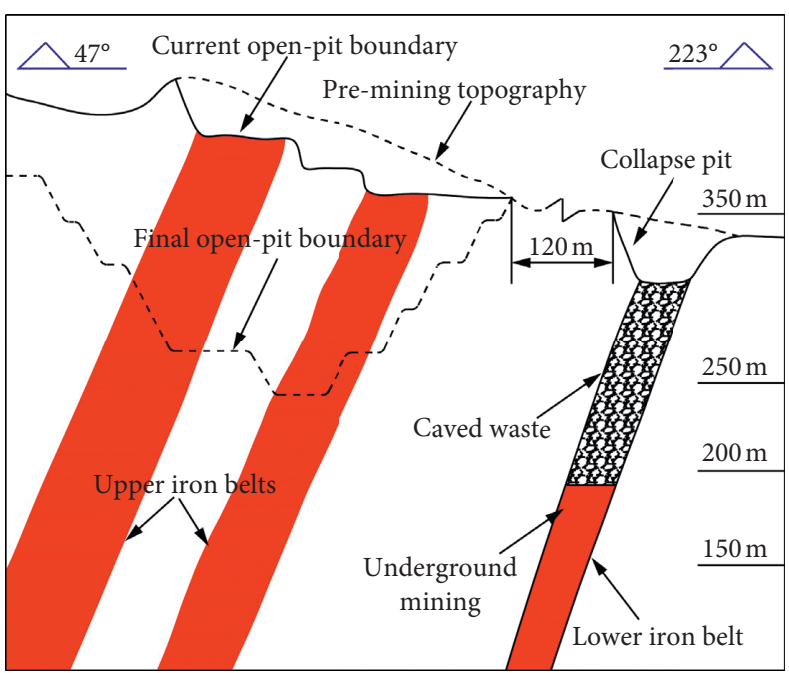

(a)

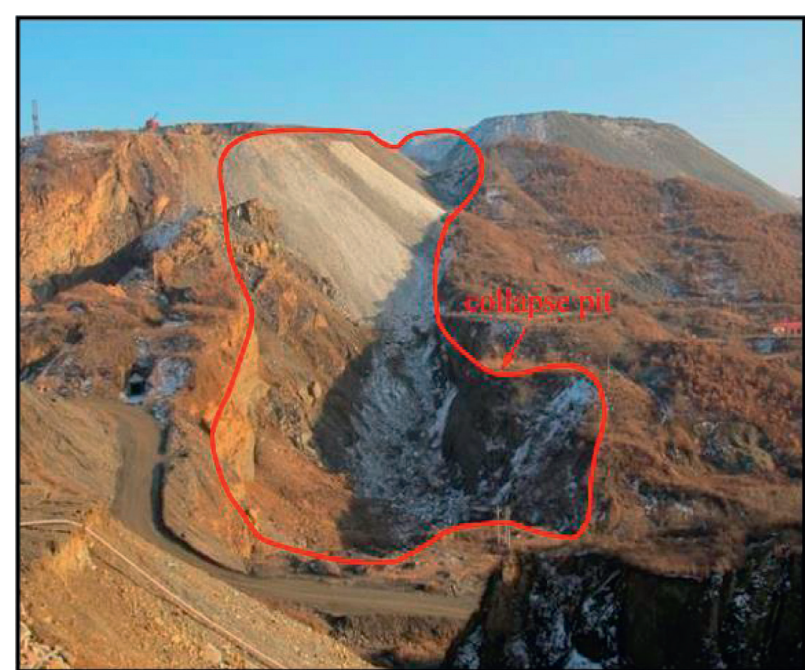

(b)

Figure 1: Engineering geological conditions in the southeast mining area. (a) Schematic diagram of mining status. (b) Collapse pit formed underground mining.

\section{Numerical Simulation}

3.1. Numerical Model. Considering that the granular rock has a clear effect on controlling the strata movement, the numerical simulations of the excavation and filling in the lower iron belt are conducted to research the ultimate depth of underground mining. Refer to the Figure 1(a), the mining condition of the southeastern mining area of the Gongchangling Iron Mine is simplified to obtain the numerical model calculation foundation simplified model (as shown in Figure 2). The size of the model is $550 \mathrm{~m} \times 150 \mathrm{~m}$ (length $\times$ width), the height of the left model boundary is $445 \mathrm{~m}$, the height of the right model boundary is $310 \mathrm{~m}$, the angle between the upper surface of model, and the horizontal plane is $15^{\circ}$ approximately. The height of the collapse pit is $40 \mathrm{~m}$, and the sublevel height of underground mining is $20 \mathrm{~m}$. To obtain more displacement monitoring information, the distance between the rightmost monitoring point and the collapse pit is set to $15 \mathrm{~m}$, and the distance between monitoring points is also $15 \mathrm{~m}$. The distance between the adjacent open-pit area and the collapse pit is $120 \mathrm{~m}$.

Figure 3(a) is a three-dimensional finite element analysis model based on FLAC ${ }^{3 \mathrm{D}}$. Figure $3(\mathrm{~b})$ is a slice in the $X Z$ direction $(Y=75)$. The displacement boundary conditions of the model include (1) fixed $X$-direction displacement at the left and right boundaries; (2) fixed $Y$-direction displacement at the front and back boundaries; (3) fixed all $X, Y, Z$ direction displacements at the bottom boundary; (4) free boundary at the top of the model.

The excavation in the numerical model is consistent with the southeast mining area in the Gongchangling Iron Mine and is divided into seven stages. The first stage is excavated to the current $190 \mathrm{~m}$ mining level, the second stage is excavated to $150 \mathrm{~m}$ level, and then the following excavation height of each stage is changed to $20 \mathrm{~m}$ because of the sublevel caving mining method. The filling follows the excavation in the each

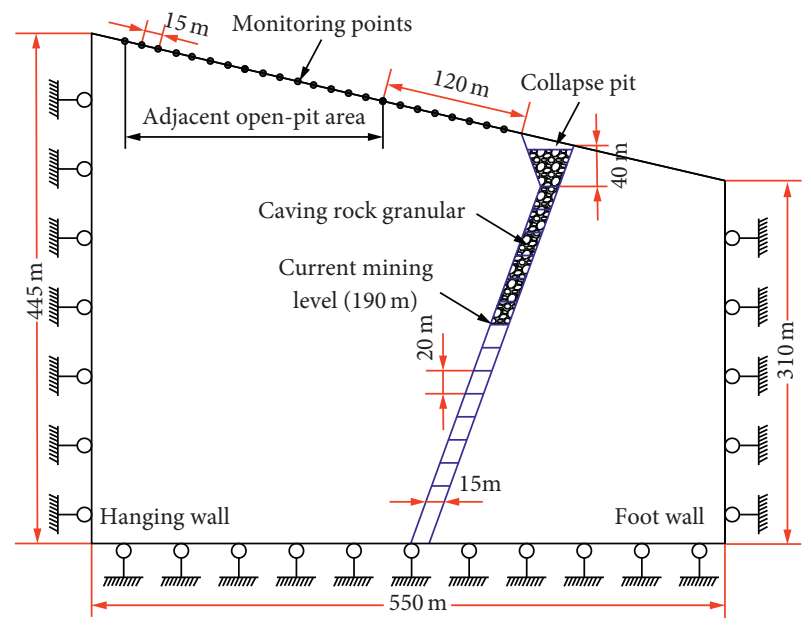

Figure 2: The schematic diagram of numerical simulation.

stage. The stages of excavation and filling in the working condition are shown in Table 1 . The numbers of excavation and filling in Table 1 are shown in Figure 3(b).

3.2. Mechanical Parameters. The Mohr-Coulomb criterion with a tension cut-off is adopted for the rock mass and backfill in the numerical simulation. In this part, a method for calculating mechanical parameters for numerical simulation is introduced by using the Hoek-Brown criterion and the Mohr-Coulomb criterion. The empirical relationships of strength and modulus between the rock mass and the intact rock have been studied by using the geological strength index (GSI) and the rock mass rating (RMR) system [36-38]. Hoek and Brown put forward the famous failure criterion of jointed rock mass $[39,40]$, which is summarized as follows: 


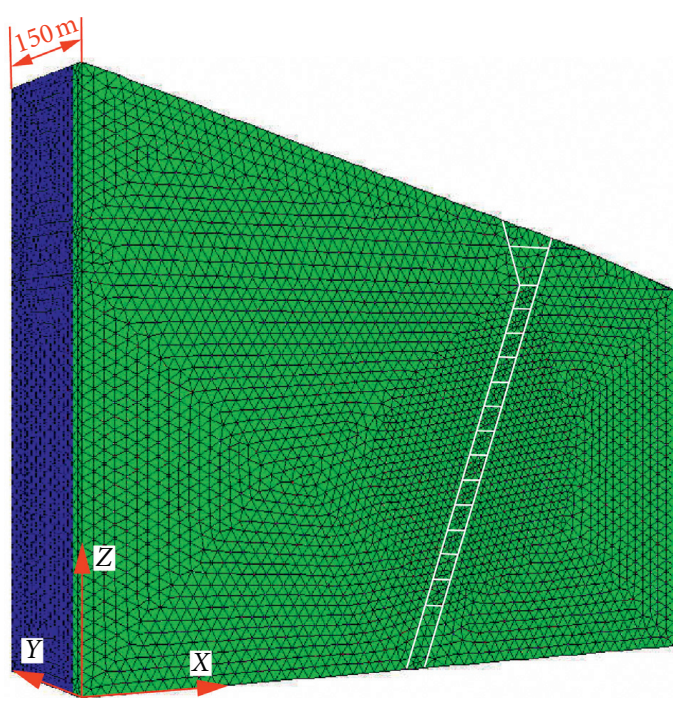

(a)

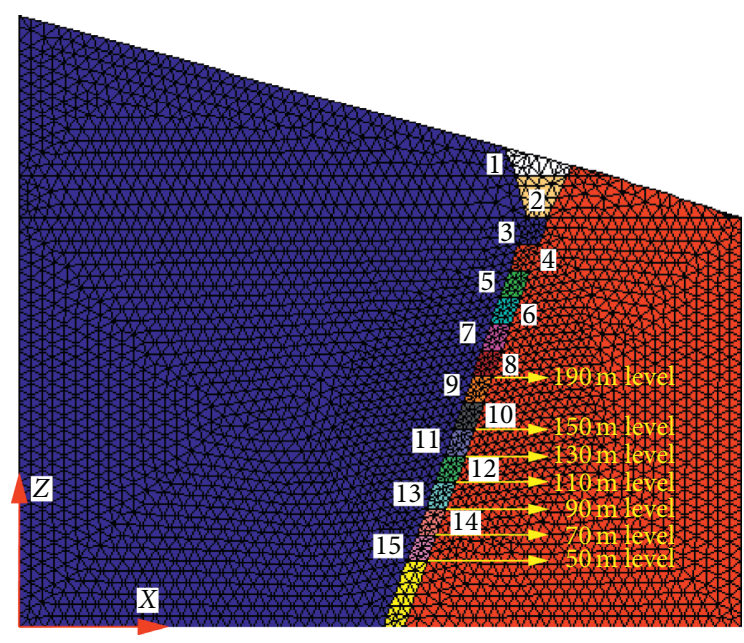

(b)

FIgURE 3: Numerical model of the lower iron belt of the southeast mining area in the Gongchangling Iron Mine: the numbers in (b) are the sequence of excavation or filling. (a) The three-dimensional finite element model. (b) The slice in the $X Z$ direction $(Y=75)$.

TABle 1: The stages of excavation and filling.

\begin{tabular}{lccc}
\hline Mining stage & Excavation number & Filling number & Mining level (m) \\
\hline First stage & $1,2,3,4,5,6,7,8$ & $1,2,3,4,5,6,7,8$ & Surface to 190 \\
Second stage & 9,10 & 9,10 & 190 to 150 \\
Third stage & 11 & 11 & 150 to 130 \\
Fourth stage & 12 & 12 & 130 to 110 \\
Fifth stage & 13 & 13 & 110 to 90 \\
Sixth stage & 14 & 14 & 90 to 70 \\
Seventh stage & 15 & 15 & 70 to 50 \\
\hline
\end{tabular}

$$
\sigma_{1}=\sigma_{3}+\sigma_{c}\left(m_{b} \frac{\sigma_{3}}{\sigma_{c}}+s\right)^{a},
$$

where $\sigma_{1}, \sigma_{3}$ are the maximum and minimum effective principal stresses at failure, respectively, $m_{b}$ is the value of the Hoek-Brown constant $m$ for the rock mass, $s$ and $a$ are constants which depend upon the rock mass characteristics, $\sigma_{c}$ is the uniaxial compressive strength of the intact rock pieces.

The values of these constants should be determined by statistical analysis of the results of a set of triaxial tests on the prepared core samples. The relationship of the parameters GSI, $m$, and $m_{b}$ is shown as follows [41]:

$$
m_{b}=m \exp \left(\frac{\mathrm{GSI}-100}{28}\right)
$$

When GSI $<25, s=0$, then $a$ can be expressed as [41]

$$
a=0.65-\frac{\mathrm{GSI}}{200} \text {. }
$$

When GSI $>25, a=0.5$, then $s$ can be expressed as [41]

$$
s=\exp \left(\frac{\mathrm{GSI}-100}{9}\right)
$$

When GSI $>25, a=0.5$, and $\sigma_{1}=0$, the uniaxial tensile strength of rock mass $\sigma_{t}$ can be obtained by equation (2), as follows:

$$
\sigma_{t}=\frac{\sigma_{c}}{2}\left(m_{b}-\sqrt{m_{b}^{2}+4 s}\right) .
$$

The relationship between the elastic modulus of rock mass $E_{m}$ and GSI can be expressed as [41]

$$
E_{m}=\sqrt{\frac{\sigma_{c}}{100}} 10^{\mathrm{GSI}-10 / 40}
$$

The parameters of $a, m$, and GIS can be obtained by geological survey, and the parameter $\sigma_{c}$ can be obtained by point load test [42]. Then, the parameters $m_{b}$ and $s$ can be solved by equations (2) and (4), respectively. The basic quality indexes of the ore body and surrounding rock of the southeast mining area in the Gongchangling Iron Mine are shown in Table 2.

According to the Mohr-Coulomb failure criterion [43], the relationship of $\sigma_{1}$ and $\sigma_{3}$ is expressed as

$$
\sigma_{1}=\frac{1+\sin \phi}{1-\sin \phi} \sigma_{3}+\frac{2 c \cdot \cos \phi}{1-\sin \phi},
$$


TABLE 2: The basic quality indexes of the southeast mining area in the Gongchangling Iron Mine.

\begin{tabular}{lcccccc}
\hline Material & $\sigma_{c}(\mathrm{MPa})$ & GSI & $a$ & $m$ & $m_{b}$ & \multicolumn{1}{c}{$s$} \\
\hline Hanging wall & 55.5 & 67 & 0.5 & 8 & 2.46 & 11 \\
Foot wall & 100 & 77 & 0.5 & 25 & 0.026 \\
Ore body & 113.4 & 82 & 0.5 & 24 & 12.6 & 0.135 \\
\hline
\end{tabular}

where $\varphi$ is the angle of internal friction of the material, and $c$ is the cohesion of the material.

Define the parameter $\sigma_{m c}$ as the uniaxial compressive strength of rock mass, equation (7) can be expressed as [40]

$$
\sigma_{1}=\sigma_{m c}+k \sigma_{3}
$$

where $\sigma_{m c}=2 c \cdot \cos \varphi /(1-\sin \varphi)$ and $k=(1+\sin \varphi) /(1-$ $\sin \varphi)$.

Then, the parameter $c$ can be expressed as

$$
c=\frac{\sigma_{m c}}{2 \sqrt{k}}
$$

When $0<\sigma_{3}<0.25 \sigma_{c}$, the triaxial test results of rock mass are consistent with Hoek-Brown criterion and Mohr-Coulomb criterion [40]. When the value of $\sigma_{3}$ is assigned, the value of $\sigma_{1}$ can be calculated by equation (1). Therefore, the parameter values of $\sigma_{m c}$ and $k$ are solved by the least square method. Then, the parameter $c$ can be obtained by equation (9). According to the above process, the rock mass mechanical parameters of the Gongchangling Iron Mine can be obtained, which are shown in Table 3 . It is worth noting that the granular rock filled into the collapse pit can be simplified to the degraded rock mass [44].

3.3. Modeling Results. Under the condition that backfilling granular rock to collapse pit on mining, the simulation nephograms for horizontal displacement and vertical displacement are shown in Figures 4 and 5, respectively. The values of the horizontal displacement and vertical displacement of the monitoring points in Figure 2 are shown in the Figures 6(a) and 6(b). The horizontal displacement and vertical displacement can be roughly divided into three areas: no-impact zone, rapid increase zone, and stable zone (as shown in Figures 6(a) and 6(b)). The vertical displacement is greater than the horizontal displacement in the same monitoring point. In addition, the displacement of all monitoring points increases with the underground mining depth. However, the displacement of the monitoring points in the adjacent open-pit area is greatly reduced and converges to zero under the condition of each underground mining depth, which indicates that the surface deformation is inversely proportional to the distance from the collapse pit.

The indicators of surface movement and deformation generally include the horizontal deformation $\varepsilon$, the inclined deformation $i$, and the curvature deformation $K$, which can be obtained by the horizontal displacement $\Delta X$ and the vertical displacement $\Delta Y[45]$.

The horizontal deformation $\varepsilon$ is the ratio of the difference in the horizontal displacement of two adjacent monitoring points and the horizontal distance between two adjacent monitoring points, which can be expressed as [45]

$$
\varepsilon_{j}=\frac{\Delta X_{j+1}-\Delta X_{j}}{\Delta l_{j}},
$$

where $j$ is the number of the monitoring points, $j=1,2,3$, $\ldots, n . \Delta X_{j}$ is the horizontal displacement at the monitoring point $j$, and $\Delta l_{j}$ is the horizontal distance between two adjacent monitoring points.

The inclined deformation $i$ is the ratio of the difference in the vertical displacement of two adjacent monitoring points and the horizontal distance between two adjacent monitoring points, which can be expressed as [45]

$$
i_{j}=\frac{\Delta Y_{j+1}-\Delta Y_{j}}{\Delta l_{j}},
$$

where $\Delta Y_{j}$ is the vertical displacement at the monitoring point $j$.

The curvature deformation $K$ is the ratio of the difference in the inclined deformation of two adjacent segments and the horizontal distance between the midpoint of two adjacent segments, which can be expressed as [45]

$$
K_{j}=\frac{i_{j+1}-i_{j}}{(1 / 2)\left(\Delta l_{j+1}+\Delta l_{j}\right)}
$$

When the value of horizontal deformation is $2 \mathrm{~mm} / \mathrm{m}$, the value of inclination is $3 \mathrm{~mm} / \mathrm{m}$, or the value of curvature is $0.2 \mathrm{~mm} / \mathrm{m}^{2}$, the buildings at the surface show initial damage [45]. To ensure the safety of open-pit and underground synergetic mining, these indicators should be below the critical value of dangerous movement.

The horizontal deformation $\varepsilon$, the inclined deformation $i$, and the curvature deformation $K$ are used to evaluate the degree of surface deformation [45]. As shown in Figures 6 (c) $6(\mathrm{e})$, the value of the horizontal deformation, inclined deformation, and curvature deformation is increased with the underground mining depth. Similarly, the three indicators of the monitoring points in the adjacent open-pit area are greatly reduced and converge to zero under the condition of each underground mining depth. Meanwhile, the maximum values of the horizontal deformation and the curvature deformation are below the critical value of dangerous movement. However, as shown in Figure 6(d), the maximum values of the inclined deformation in the $70 \mathrm{~m}$ and $50 \mathrm{~m}$ mining levels exceed the critical value of dangerous movement. Considering that the monitoring point above the critical value of the inclined deformation is close to the openpit area, the ultimate underground mining depth is determined at $90 \mathrm{~m}$ level to ensure the safety of the open-pit and underground synergetic mining. 
TABLE 3: The parameters of rock mass in the southeast mining area.

\begin{tabular}{lcccccc}
\hline Material & $\rho\left(\mathrm{g} \cdot \mathrm{cm}^{-3}\right)$ & $\sigma_{m c}(\mathrm{MPa})$ & $\sigma_{t}(\mathrm{MPa})$ & $\phi\left(^{\circ}\right)$ & $c(\mathrm{MPa})$ & $E_{m}(\mathrm{GPa})$ \\
\hline Hanging wall & 2.7 & 5.99 & 1.07 & 35 & 0.34 & 8.82 \\
Foot wall & 2.7 & 8.51 & 1.71 & 52 & 0.67 & 17.31 \\
Ore body & 3.7 & 10.83 & 2.21 & 53 & 0.85 & 0.31 \\
Granular rock & 2.0 & 0.05 & 0.01 & 18 & 0.01 & 23.1 \\
\hline
\end{tabular}

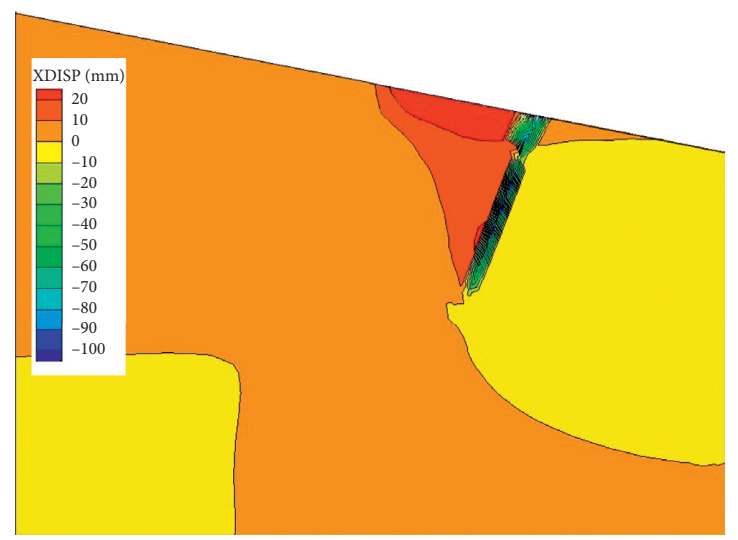

(a)

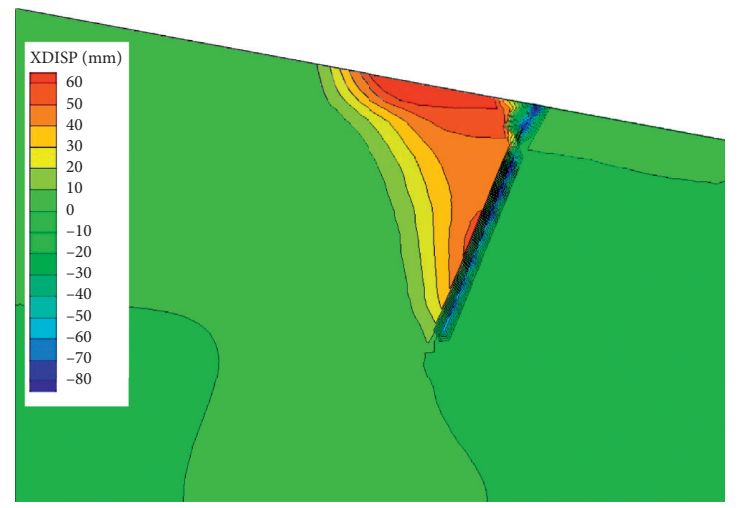

(c)

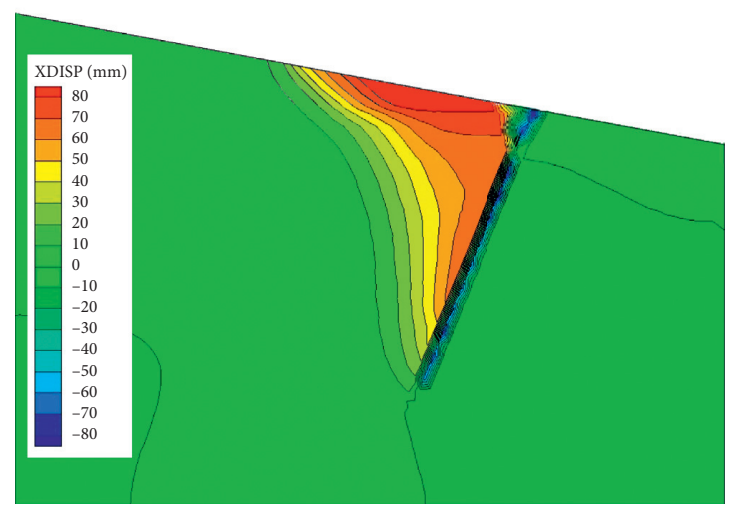

(e)

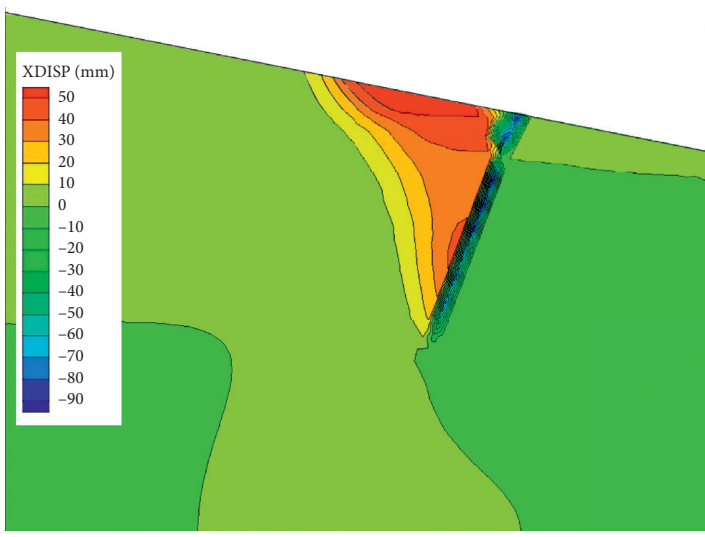

(b)

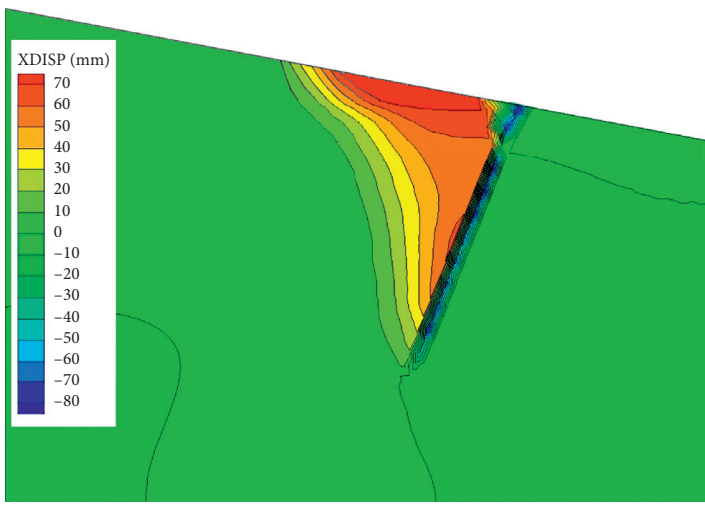

(d)

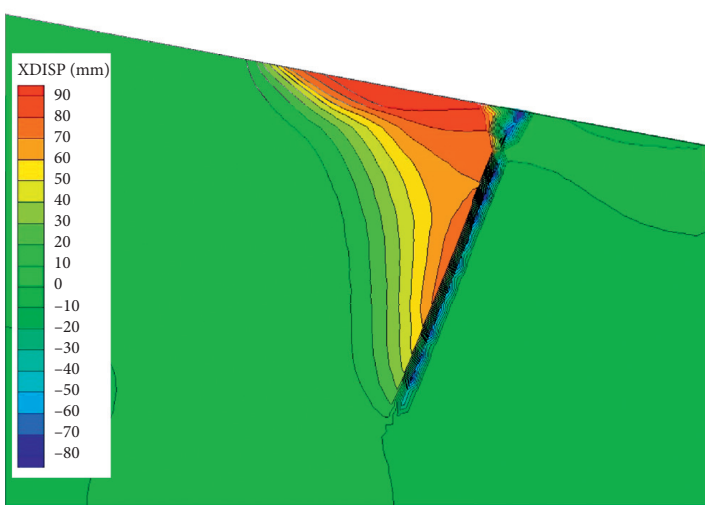

(f)

Figure 4: Continued. 


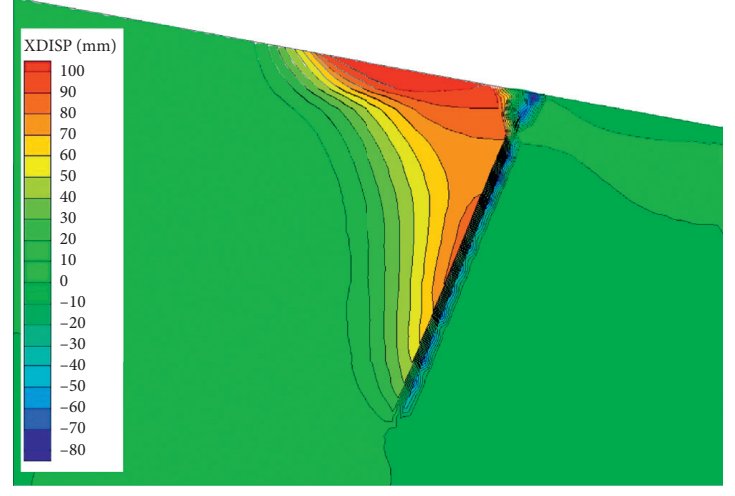

$(\mathrm{g})$

Figure 4: The simulation nephograms for horizontal displacement. (a) $190 \mathrm{~m}$ level. (b) $150 \mathrm{~m}$ level. (c) $130 \mathrm{~m}$ level. (d) $110 \mathrm{~m}$ level. (e) $90 \mathrm{~m}$ level. (f) $70 \mathrm{~m}$ level. (g) $50 \mathrm{~m}$ level.

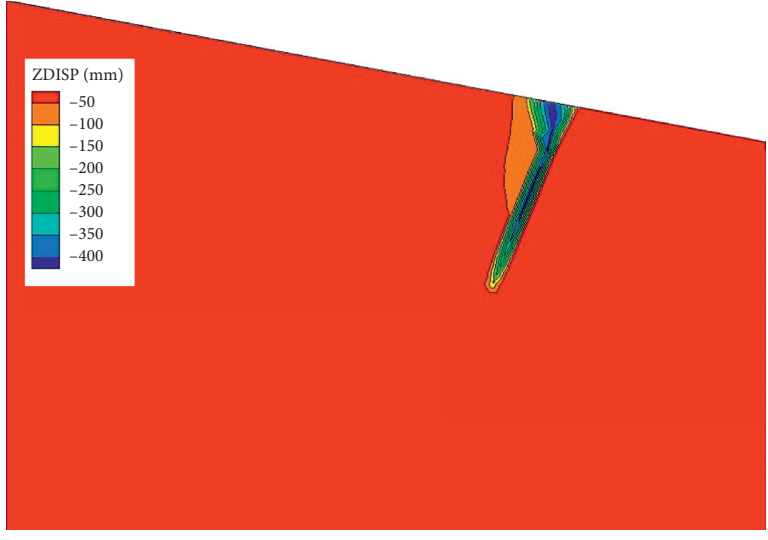

(a)

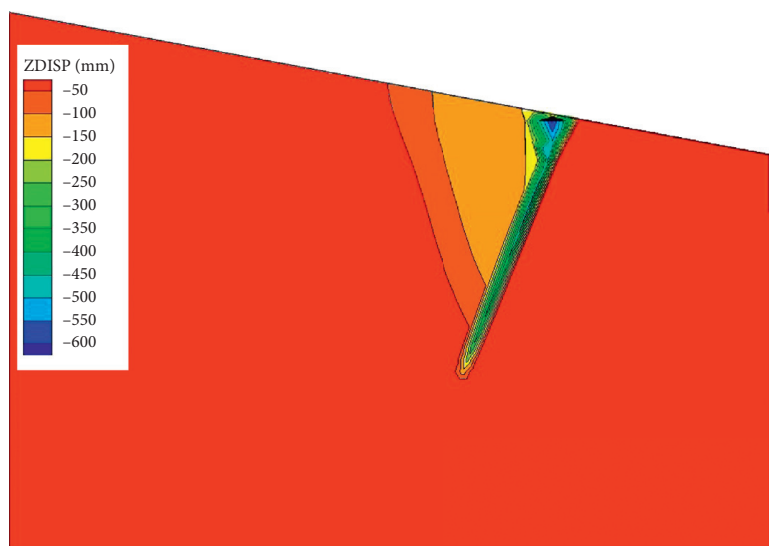

(c)

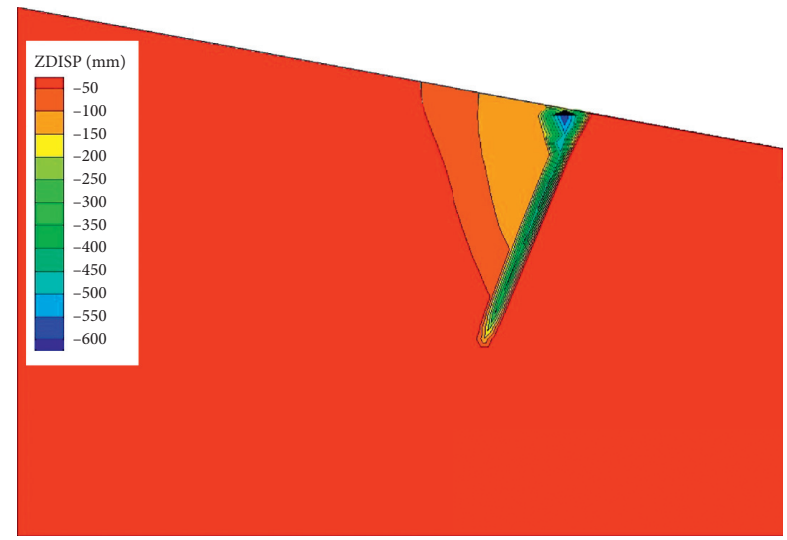

(b)

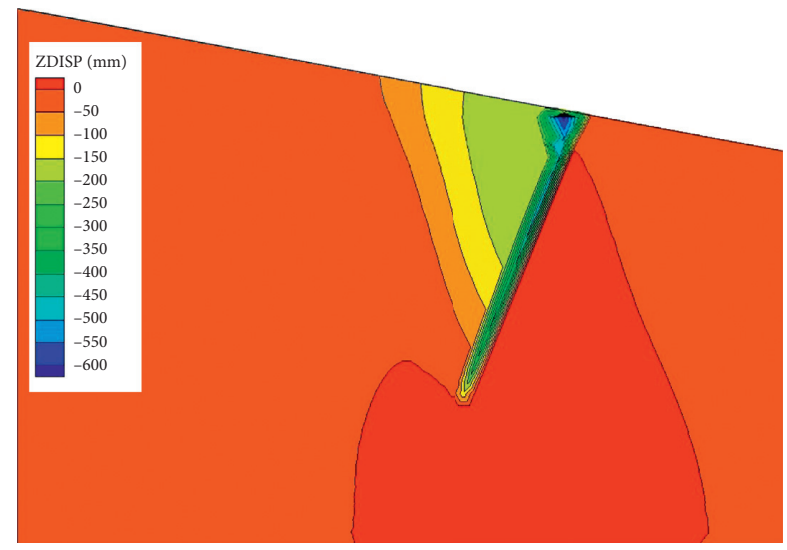

(d)

Figure 5: Continued. 


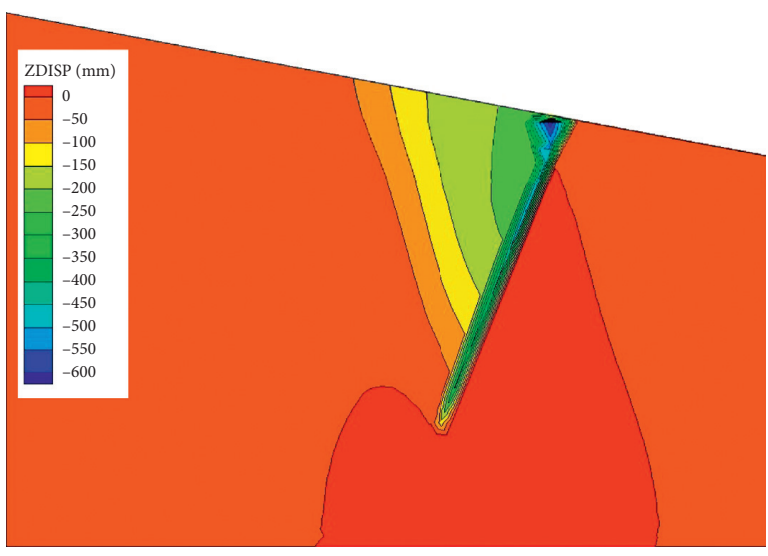

(e)

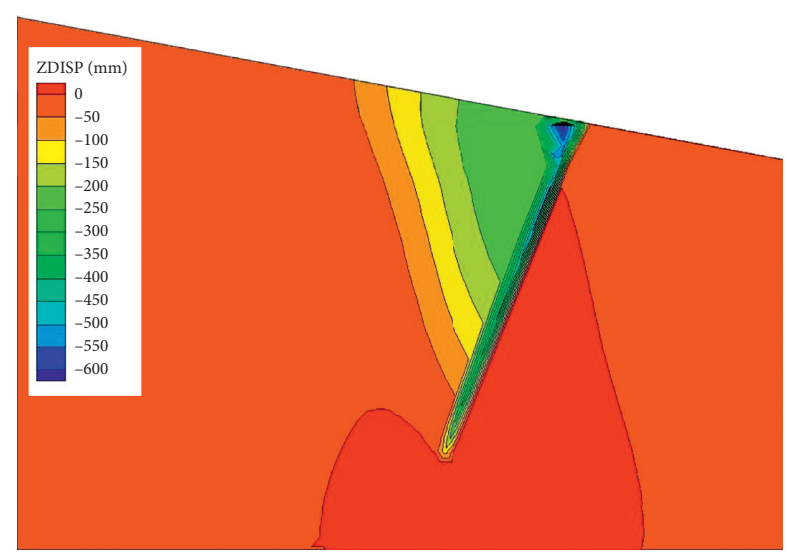

(f)

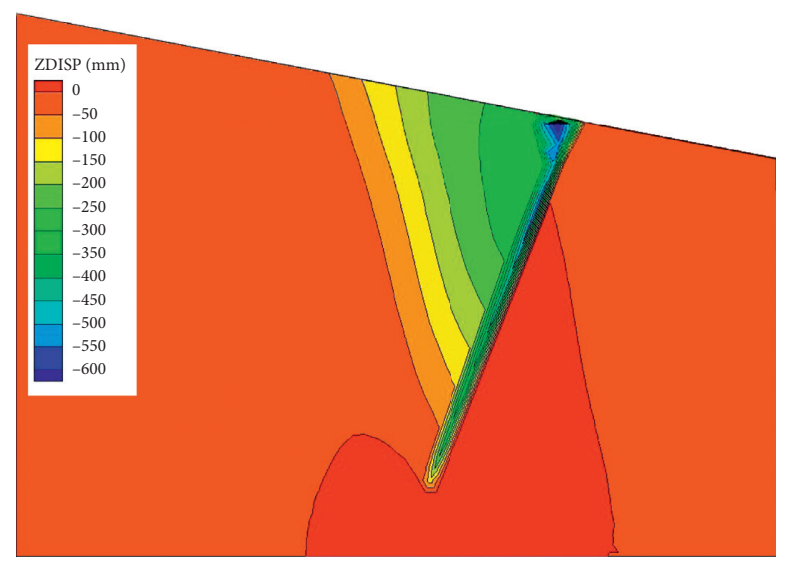

(g)

Figure 5: The simulation nephograms for vertical displacement. (a) $190 \mathrm{~m}$ level. (b) $150 \mathrm{~m}$ level. (c) $130 \mathrm{~m}$ level. (d) $110 \mathrm{~m}$ level. (e) $90 \mathrm{~m}$ level. (f) $70 \mathrm{~m}$ level. (g) $50 \mathrm{~m}$ level.

\section{Mechanical Model for Progressive Hanging Wall Caving}

The surface subsidence of the lower ore belt in the southeast mining area in the Gongchangling Iron Mine is a typical form of progressive hanging wall caving. Hoek [46] derives the equation of the subsidence range of hanging wall based on the limit equilibrium theory. However, the equation ignores the effect of granular rock in the scope of mining. Therefore, the mechanical model considering the effect of granular rock (as shown in Figure 7) on the progressive hanging wall of the collapse pit caving is established to improve that equation according to the results of the numerical simulation of the collapse pit in the southeast mining area. Based on the mechanical model and the range of surface caving, the ultimate underground mining depth can be calculated.

As shown in Figure 7, $\theta$ is the inclination of the surface, $\alpha$ is the inclination of the ore body, $\beta_{0}$ is the inclination of the initial failure surface, $\beta_{1}$ is the inclination of the subsequent failure surface, $H_{0}$ is the mining depth of the initial failure, $H_{c}$ is the caving body height of the initial failure, $H_{1}$ is the mining depth of subsequent failure, and $Z$ is the depth of subsequent surface cracks. According to the geometric relationship, we can obtain some important equations. Specifically expressed as

The weight $W_{1}$ of the upper sliding wedge BCDEF:

$$
W_{1}=\frac{1}{2} \gamma\left[\frac{H_{1}^{2} \sin \left(\alpha+\beta_{1}\right) \sin (\alpha+\theta)}{\sin ^{2} \alpha \sin \left(\beta_{1}-\theta\right)}-\frac{H_{0}^{2} \sin \left(\alpha+\beta_{0}\right) \sin (\alpha+\theta)}{\sin ^{2} \alpha \sin \left(\beta_{0}-\theta\right)}-\frac{Z^{2} \cos \theta \cos \beta_{1}}{\sin \left(\beta_{1}-\theta\right)}\right],
$$

where $\gamma$ is the bulk weight of the rock mass in the hanging wall.
The area $A_{1}$ per unit thickness along the failure surface $\mathrm{CD}$ is 


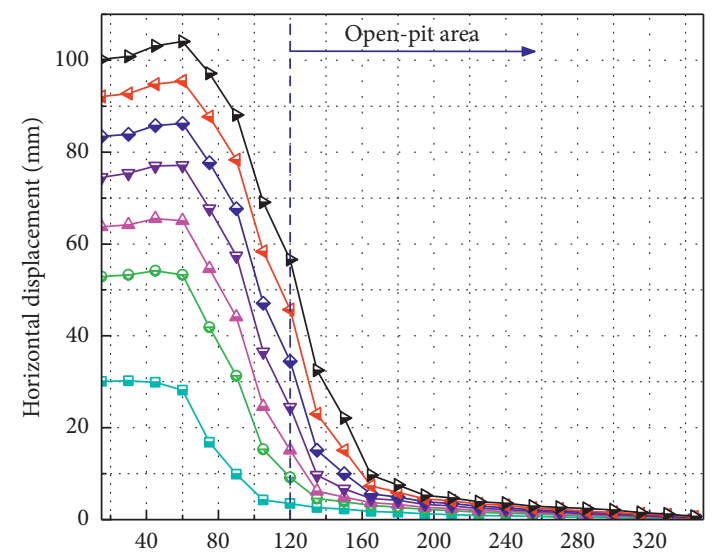

The distance from the monitoring point to the collapse pit (m)

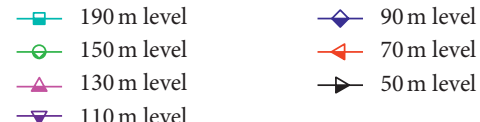

(a)

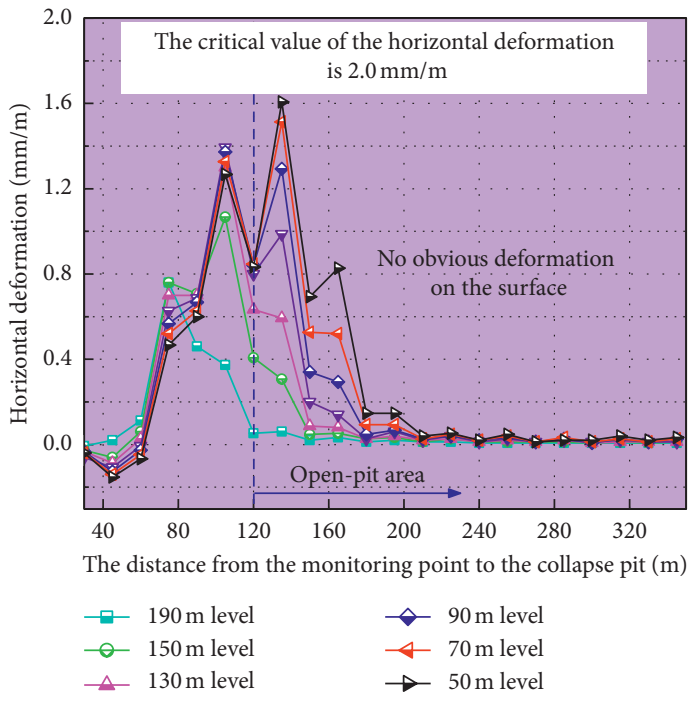

(c)

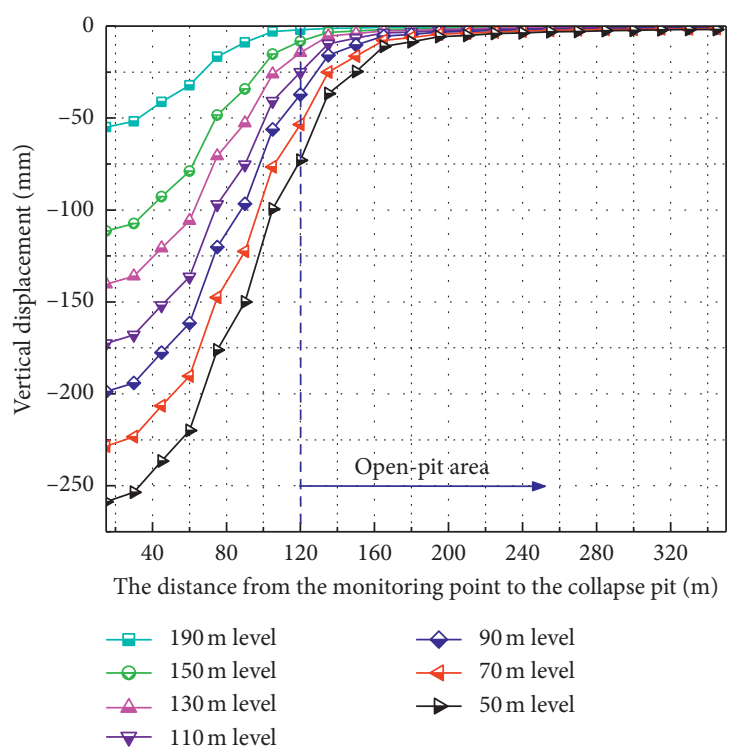

(b)

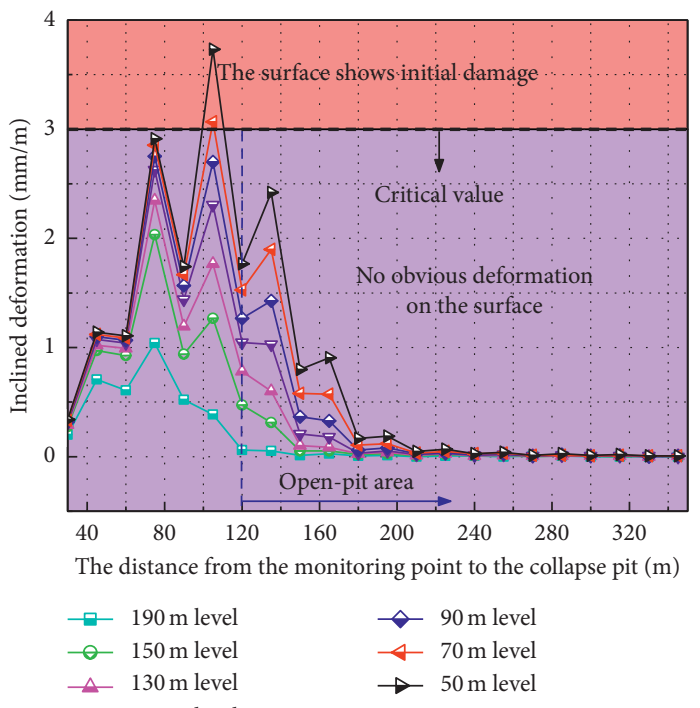

(d)

Figure 6: Continued. 


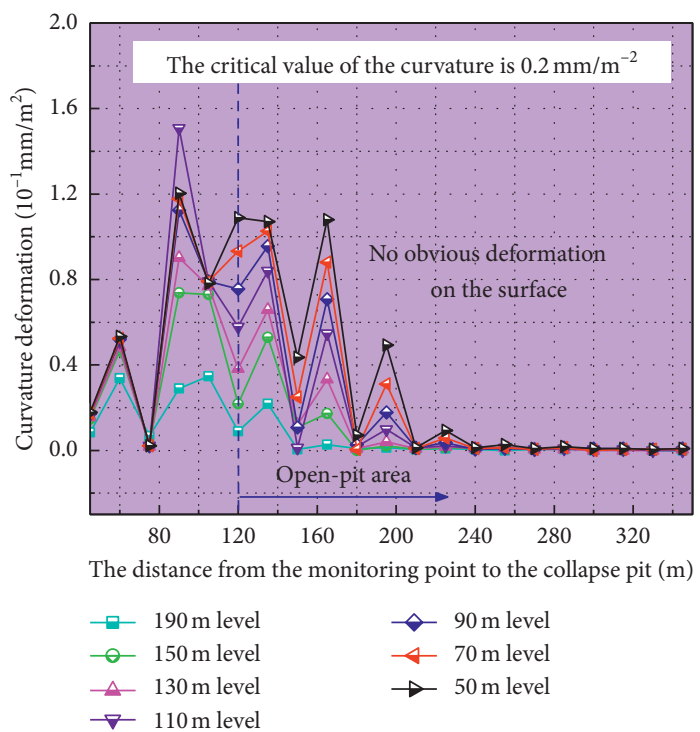

(e)

Figure 6: The monitoring points deformation characteristics in numerical model with backfilling. (a) The horizontal displacement. (b) The vertical displacement. (c) The horizontal deformation. (d) The inclined deformation. (e) The curvature deformation.

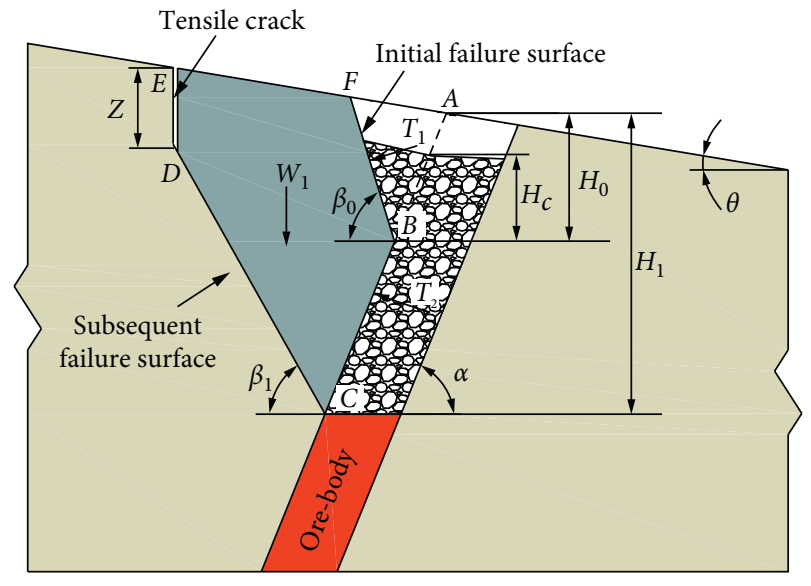

FIGURE 7: The mechanical model of limiting equilibrium analysis of progressive hanging wall caving.

$$
A_{1}=\frac{H_{1} \sin (\alpha+\theta)-Z \sin \alpha \cos \theta}{\sin \alpha \sin \left(\beta_{1}-\theta\right)} .
$$

The pushing force of the caving body acting on the potential slip body can be divided into two parts, which are shown in Figure 7 . The first part is the pushing force $T_{1}$ of the caving body acting on the initial sliding surface. The second part is the pushing force $T_{2}$ of the caving body on the upper surrounding rock. The expression of $T_{1}$ and $T_{2}$ can be obtained by mechanical analysis as follows:

$$
\begin{aligned}
& T_{1}=\frac{1}{2} \gamma_{c} H_{c}^{2} K_{p_{1}}, \\
& T_{2}=\frac{1}{2} \gamma_{c}\left(H_{1}-H_{0}\right) K_{p_{2}},
\end{aligned}
$$

where $\gamma_{c}$ is the bulk weight of the caving body. The parameter $K_{p}$ is the lateral pressure coefficient, which can be expressed as [47]

$$
K_{p}=\frac{\cos ^{2}\left(\phi_{c}+\varepsilon\right)}{\cos ^{2} \varepsilon \cos (\varepsilon-\delta)\left[1-\sqrt{\sin \left(\phi_{c}+\delta\right) \sin \left(\left(\phi_{c}+\theta_{c}\right) / \cos (\varepsilon-\delta) \cos \left(\varepsilon-\theta_{c}\right)\right.}\right]^{2}}
$$

where $\delta$ is the angle between the lateral pressure and the normal of the sliding surface, according to the roughness of the hanging wall on the collapse pit, $\delta=0.5 \phi_{c}$; $\varepsilon$ is the angle between the hanging wall on the collapse pit and the vertical direction, $\varepsilon_{1}=90^{\circ}-\beta_{0}, \varepsilon_{2}=\alpha-90^{\circ}$; and $\theta_{c}$ is the angle between the surface of the rock granular in the collapse pit and the horizontal plane, according to the state of the rock granular in the Gongchangling collapse pit, $\theta_{c}=0$.

Taking the Mohr-Coulomb criterion as the failure criterion for wedge rock masses, then 


$$
\begin{aligned}
\tau & =c^{\prime}+\sigma_{n}^{\prime} \tan \phi^{\prime}, \\
\sigma_{n}^{\prime} & =\frac{W \cos \beta_{1}+T_{1} \cos \phi_{1}+T_{2} \sin \phi_{2}}{A}, \\
\tau & =\frac{W \sin \beta_{1}+T_{1} \sin \phi_{1}-T_{2} \cos \phi_{2}}{A},
\end{aligned}
$$

where $\tau$ is the effective shear stress on the failure surface, $\sigma_{n}^{\prime}$ is the effective normal stress on the failure surface, $\phi^{\prime}$ is the effective internal friction angle, $c^{\prime}$ is the effective cohesion, $\varphi$ is the angle between the lateral pressure of the ore body and the normal of the subsequent failure surface, $\phi_{1}=\beta_{1}-\beta_{0}+\delta, \phi_{2}=\beta_{1}+\alpha+\delta-90^{\circ}$.

Substituting equations (13)-(17) and equations (19) and (20) into equation (18) and rearranging the equation yield

$$
\begin{aligned}
& \left(\frac{\gamma H_{1}}{c^{\prime}}\right)^{2} \frac{\sin (\theta+\alpha) \sin \left(\beta_{1}+\alpha\right) \sin \left(\beta_{1}-\phi^{\prime}\right)}{\sin ^{2} \alpha}+\frac{\gamma_{c}}{\gamma}\left(\frac{\gamma H_{c}}{c^{\prime}}\right)^{2} K_{P 1} \sin \left(\varphi_{1}-\phi^{\prime}\right) \sin \left(\beta_{1}-\theta\right)+\frac{2 \gamma Z \cos \theta}{c^{\prime}} \cos \phi^{\prime} \\
& -2 \frac{\gamma H_{1}}{c^{\prime}} \frac{\sin (\theta+\alpha) \cos \phi^{\prime}}{\sin \alpha}-\frac{\gamma_{c}}{\gamma}\left(\frac{\gamma H_{1}-\gamma H_{0}}{c^{\prime}}\right)^{2} K_{P 2} \cos \left(\phi_{2}-\phi^{\prime}\right) \sin \left(\beta_{1}-\theta\right) \\
& -\left(\frac{\gamma H_{0}}{c^{\prime}}\right)^{2} \frac{\sin (\theta+\alpha) \sin \left(\beta_{0}+\alpha\right) \sin \left(\beta_{1}-\phi^{\prime}\right) \sin \left(\beta_{1}-\theta\right)}{\sin ^{2} \alpha \sin \left(\beta_{0}-\theta\right)}-\left(\frac{\gamma Z}{c^{\prime}}\right)^{2} \cos \theta \cos \beta_{1} \sin \left(\beta_{1}-\phi^{\prime}\right)=0
\end{aligned}
$$

Differentiating equation (21) with respect to $Z$ and making the result equal to zero, the critical value of $Z$ can be expressed as

$$
Z=\frac{c^{\prime} \cos \phi^{\prime}}{\gamma \cos \beta_{1} \sin \left(\beta_{1}-\phi^{\prime}\right)} .
$$

Differentiating equation (21) with respect to $\beta_{1}$ and setting $\partial H_{1} / \partial \beta_{1}$ equal to zero, we can obtain the expression of the dip angle of the subsequent critical failure surface:

$$
\beta_{1}=\frac{1}{2}\left(\phi^{\prime}+\cos ^{-1} \frac{X}{\sqrt{X^{2}+Y^{2}}}\right),
$$

where $X$ and $Y$ are expressed as equations (24) and (25), respectively.

$$
\begin{aligned}
X= & \left(\frac{\gamma H_{1}}{c^{\prime}}\right)^{2} \frac{\sin (\theta+\alpha) \cos \alpha}{\sin ^{2} \alpha}+\left(\frac{\gamma H_{0}}{c^{\prime}}\right)^{2} \frac{\sin (\theta+\alpha) \sin \left(\beta_{0}+\alpha\right) \cos \theta}{\sin ^{2} \alpha \sin \left(\beta_{0}-\theta\right)}-\frac{\gamma_{c}}{\gamma}\left(\frac{\gamma H_{c}}{c^{\prime}}\right)^{2} K_{p 1} \cos \left(\beta_{0}+\theta-0.5 \phi_{c}\right) \\
& -\frac{\gamma_{c}}{\gamma}\left(\frac{\gamma H_{1}-\gamma H_{0}}{c^{\prime}}\right)^{2} K_{p 2} \cos \left(\alpha+0.5 \phi_{c}-\theta\right) \\
Y= & \left(\frac{\gamma Z}{c^{\prime}}\right)^{2} \cos \theta+\frac{\gamma_{c}}{\gamma}\left(\frac{\gamma H_{c}}{c^{\prime}}\right)^{2} K_{p 1} \sin \left(\beta_{0}+\theta-0.5 \phi_{c}\right)+\frac{\gamma_{c}}{\gamma}\left(\frac{\gamma H_{1}-\gamma H_{0}}{c^{\prime}}\right)^{2} K_{p 2} \sin \left(\alpha+0.5 \phi_{c}-\theta\right) \\
& -\left(\frac{\gamma H_{1}}{c^{\prime}}\right)^{2} \frac{\sin (\theta+\alpha)}{\sin \alpha}-\left(\frac{\gamma H_{0}}{c^{\prime}}\right)^{2} \frac{\sin (\theta+\alpha) \sin \left(\beta_{0}+\alpha\right) \sin \theta}{\sin ^{2} \alpha \sin \left(\beta_{0}-\theta\right)} .
\end{aligned}
$$

Assuming that the horizontal distance from the point $A$ to the edge of $D E$ in Figure 7 is $L$, the relationship between $L$, $\beta_{1}$, and $Z$ can be expressed by the geometric relationship:

$$
\frac{L}{\sin \left(\alpha+\beta_{1}\right)}=\frac{H_{1}-Z+L \tan \theta}{\sin \beta_{1}} \text {. }
$$

The engineering parameter values of field investigation in the southeast mining area are shown in Table 4 . The parameters $\phi^{\prime}$ and $c^{\prime}$ can be selected the values of $\phi$ and $c$ corresponding to the hanging wall in Table 3 . The minimum distance between the upper iron belts and the lower iron belt is $150 \mathrm{~m}$. At present, the upper iron belts are mined to the +388 $\mathrm{m}$ level, and the critical distance between the caving fracture and the lower iron belt is $120 \mathrm{~m}$, which can be used as a reference value for the parameter $L$.

The parameters of $Z, \beta_{1}$, and $H_{1}$ can be solved by the iterative method. Refer to the calculation method proposed by Hoek [46]: firstly, set $\beta_{1 e}=\left(\phi^{\prime}+\beta_{0}\right) / 2$ and substitute $\beta_{1 e}$ as the value of $\beta_{1}$ in equations (22) and (26) to calculate $Z$ and $H_{1}$; secondly, substitute the value of $Z$ and $H_{1}$ in equation (23) to calculate $\beta_{1}$; and finally, comparing the values of $\beta_{1 e}$ and $\beta_{1}$, if $\beta_{1 e} \neq \beta_{1}$, recalculate the value of $Z$ and $H_{1}$ with $\beta_{1}$ instead of $\beta_{1 e}$. Repeat the calculation steps until the difference between the two calculated values of $\beta_{1}$ is less than $0.1 \%$. Ultimately, we can obtain $\beta_{1}=76^{\circ}, H_{1}=241 \mathrm{~m}$, and $Z=65 \mathrm{~m}$. 
TABLE 4: The values of the engineering parameter in the southeast mining area.

\begin{tabular}{lccccccccc}
\hline Parameter & $\theta\left(^{\circ}\right)$ & $\theta_{c}\left({ }^{\circ}\right)$ & $\alpha\left(^{\circ}\right)$ & $\phi_{c}\left({ }^{\circ}\right)$ & $\beta_{0}\left({ }^{\circ}\right)$ & $\gamma\left(\mathrm{kN} / \mathrm{m}^{3}\right)$ & $\gamma_{c}\left(\mathrm{kN} / \mathrm{m}^{3}\right)$ & $H_{0}(\mathrm{~m})$ & $H_{c}(\mathrm{~m})$ \\
\hline Value & 15 & 0 & 70 & 23 & 70 & 27 & 20 & 40 & 32 \\
\hline
\end{tabular}

Considering that the surface elevation of the point $A$ in Figure 7 is $+350 \mathrm{~m}$, the ultimate underground mining level of the theoretical calculation is $+109 \mathrm{~m}$, which is different with the results of the numerical simulation. It is worth noting that the granular rock is simplified as the degraded rock mass in the numerical simulation, which increased the resistance of granular rock to the deformation of rock mass. Therefore, the ultimate underground mining depth determined by the numerical simulation is greater than the actual value. Compared with the results of the numerical simulation and theoretical calculation, the $109 \mathrm{~m}$ level is suggested as the ultimate underground mining level to ensure the safety of the open-pit and underground synergetic mining. Recall that the sublevel height of underground mining is $20 \mathrm{~m}$, the ultimate underground mining depth of the southeast mining area in the Gongchangling Iron Mine can be determined at $110 \mathrm{~m}$ level, namely, the ultimate underground mining depth is $240 \mathrm{~m}$.

\section{Surface Displacement Monitoring}

The ultimate underground mining depth of the southeast mining area in the Gongchangling Iron Mine was determined at the $110 \mathrm{~m}$ level based on numerical simulation and theoretical calculations. To control the expansion of the existing collapse pit and avoid new surface subsidence caused by underground mining, it was necessary to continuously fill the collapse pit with waste rock according to the intensity of underground mining activities [48-50]. Therefore, we suggested that the Gongchangling Iron Mine can increase the stripping and mining strength of the upper iron belts and appropriately reduce the underground mining speed of the lower iron belt to ensure coordinated mining in the open and underground. In addition, the mine can fill the collapse pit with the waste rock stripped from the open pit.

The waste rock is replenished in time to keep the collapse pit filled with granular rock when the waste rock moves down during underground mining. To improve the efficiency of rock drainage, a coordinated rock backfilling scheme along the direction of the pit and the sidewall can be adopted: (1) discard waste rock along the sidewall of the pit at the upper side of the pit (as shown in Figure 8); (2) discard the waste rock along the end of the collapse pit (as shown in Figure 8).

In addition, displacement monitoring measures to observe the formation and expansion of surface cracks were adopted. The monitoring points arranged on the exploration line can facilitate the comparative analysis of the monitoring data. As shown in Figure 9, given that the \#25 exploration line was adjacent to the middle part of the open pit and collapse pit simultaneously, the displacement monitoring points A1, A2, and A3 were set at the exploration line. The displacement of the lower boundary of the open pit is the key indicator for the open-pit and underground synergetic mining. Therefore, the distances between the monitoring points and the lower boundary of the open-pit are $10 \mathrm{~m}$, $20 \mathrm{~m}$, and $30 \mathrm{~m}$, respectively.

The displacement curves of the surface monitoring are shown in Figure 10(a). The lower iron belt was mined to the $150 \mathrm{~m}$ level using the shallow-hole shrinkage mining method in January 2015. The upper iron belts were mined to the $280 \mathrm{~m}$ level using open-pit mining when the lower iron belt was mined to the $110 \mathrm{~m}$ level using the sublevel caving method in July 2016. The underground mining was temporarily ended when the lower iron belt was mined to the $110 \mathrm{~m}$ level. Meanwhile, the open-pit mining and underground mining achieved safe and coordinated production. In terms of the coordinated rock backfilling scheme, the collapse pit was full of granular rock in January 2016. In addition, the collapse pit remained full due to continuous filling during the mining process of the lower iron-bearing belt after January 2016.

As shown in Figure 10(a), the horizontal and vertical displacements of the monitoring points of $\mathrm{A} 1, \mathrm{~A} 2$, and $\mathrm{A} 3$ increase with the increase of time and the decline of the underground mining level. Under the same time condition, the horizontal displacement of the same monitoring point is slightly larger than the vertical displacement, which is consistent with the numerical simulation results. In addition, the horizontal displacement and the vertical displacement substantially increase twice during the underground mining process. The first rapid increase occurred three months after the end of the $150 \mathrm{~m}$ level mining, and the second occurred five months after the end of the $110 \mathrm{~m}$ level mining, which indicated that the strata movement in the hanging wall lagged behind the underground mining. Obviously, the second increase is substantially smaller than the first increase. Meanwhile, the lag time of the strata movement in the second increase is longer for the first increase. The characteristic may be associated with the compactness of the backfilled waste rock increased by the squeezing of the hanging wall rock mass [22].

Similarly, the characteristic of the twice rapid increase is reflected in the curves of the horizontal deformation (Figure 10(b)), inclined deformation (Figure 10(c)), and curvature deformation (Figure 10(d)). The values of the three indicators were lower than the critical value of dangerous movement [45], which indicated that the open-pit 


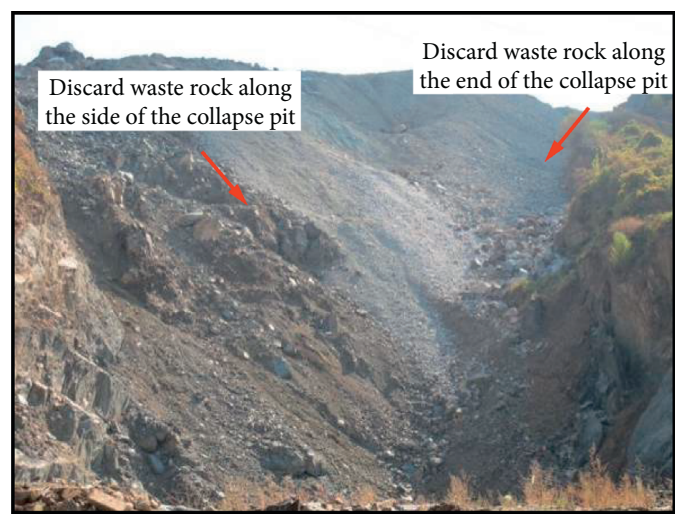

(a)

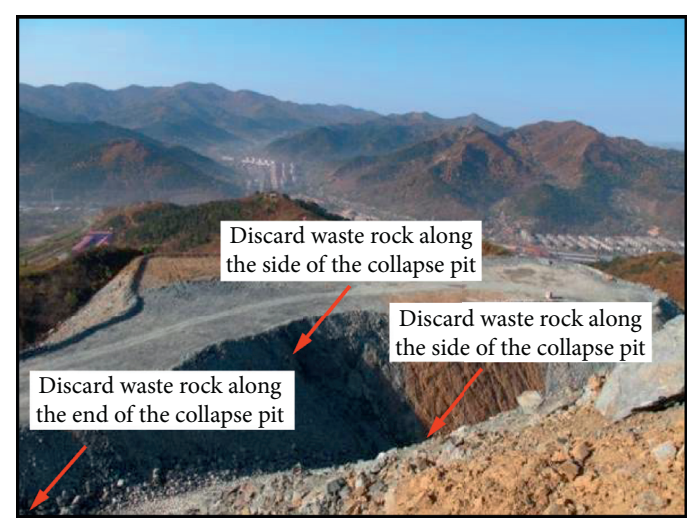

(b)

FIgURE 8: Collapse pit waste rock plan and site map. (a) Left view; (b) Top view.

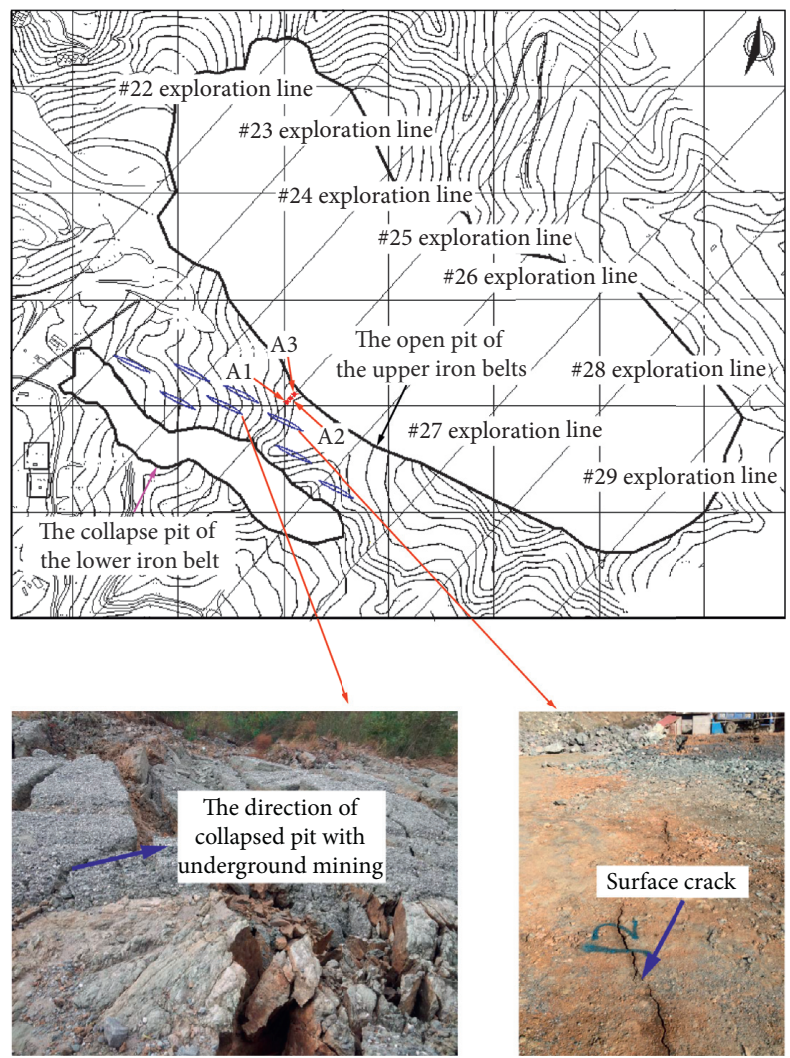

Figure 9: The location of monitoring point and the surface fracture.

mining can be produced safely when the lower iron belt was mined to $110 \mathrm{~m}$ level. In addition, the surface cracks mainly occurred between monitoring point $\mathrm{A} 1$ and the edge of the collapse pit by investigating the on-site cracks in the Gongchangling Iron Mine. Tensile cracks with shallow depths appeared on the upper side of the collapse pit.
Meanwhile, there were no tensile cracks or sudden settlements between the collapse pit and the open pit. The results revealed that the waste rock backfilling scheme can increase the operational mining years of the lower iron belt and ensure the safety and efficiency of mining operations of the upper iron belts and the lower iron belt. 

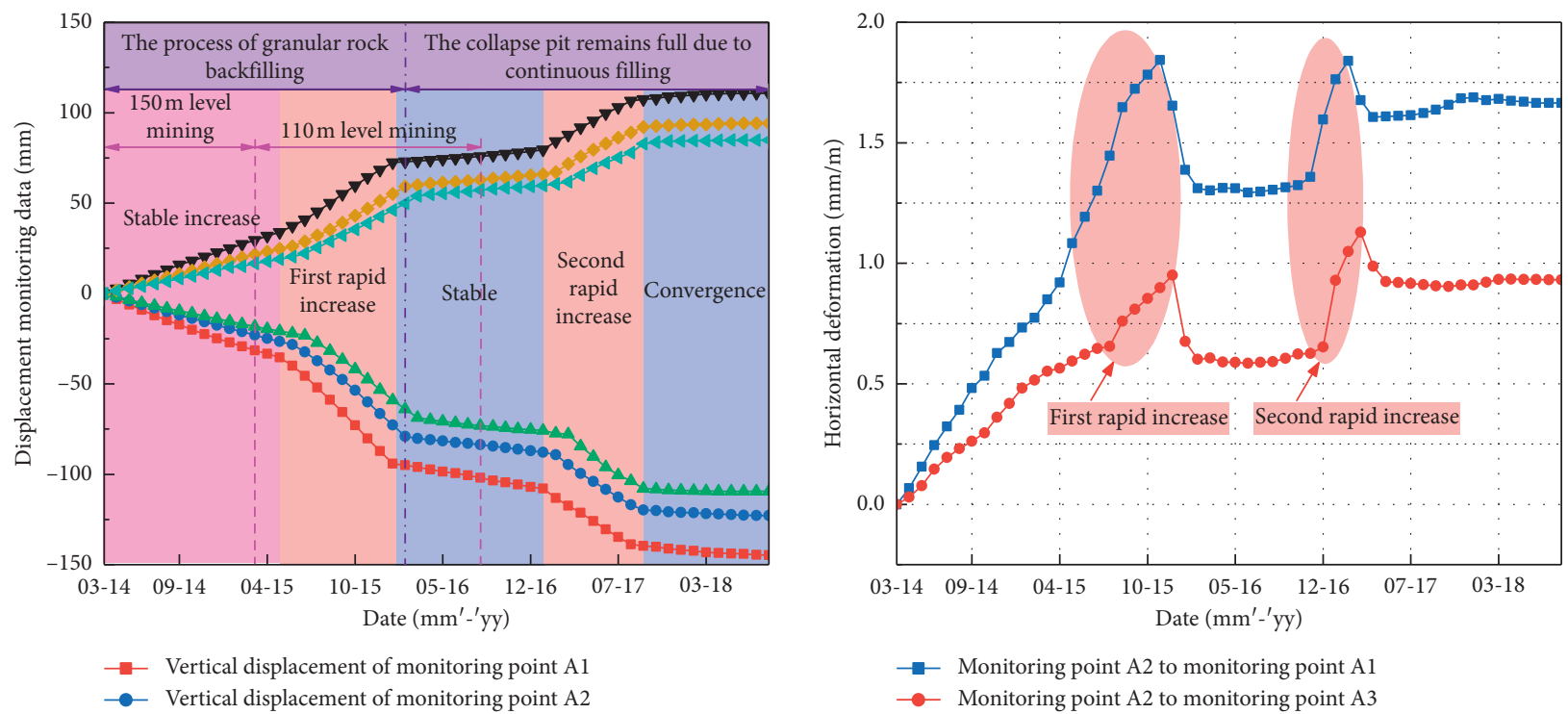

- Vertical displacement of monitoring point A2
- Vertical displacement of monitoring point A3
- Horizontal displacement of monitoring point A1
- Horizontal displacement of monitoring point A2
- Horizontal displacement of monitoring point A3

(a)

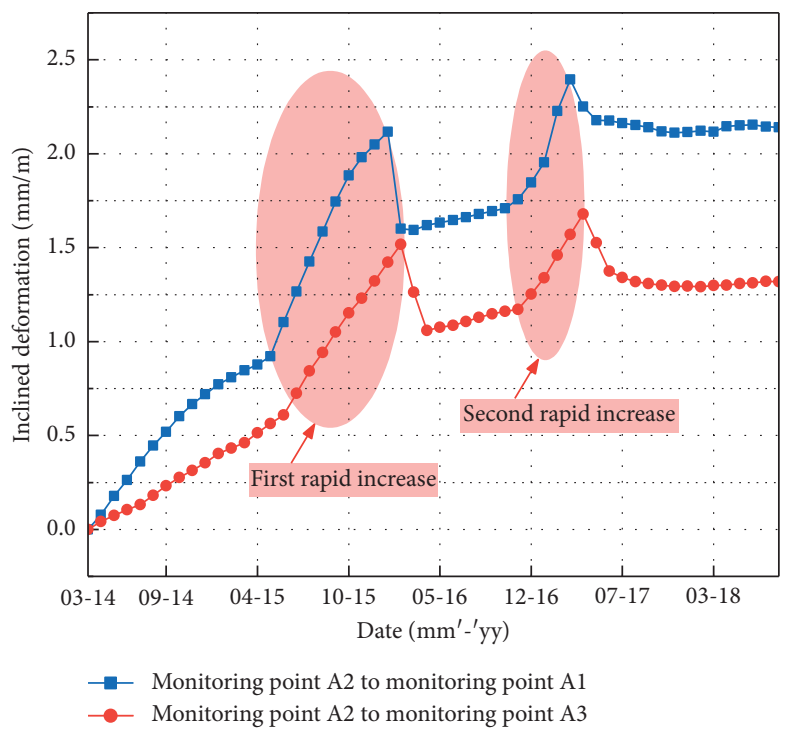

(b)

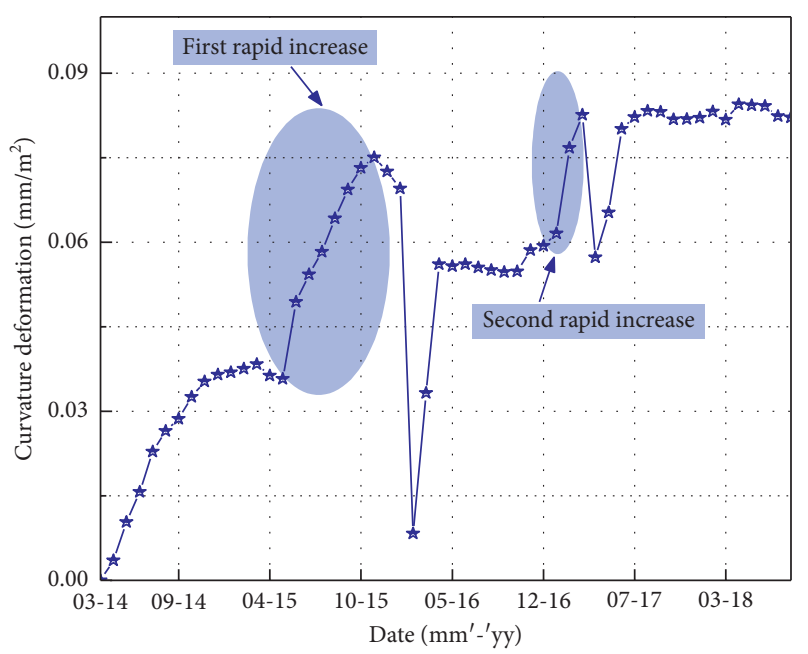

(c)

(d)

FIgURE 10: The deformation characteristics of the monitoring points in the area between the collapse pit and the open-pit mining. (a) The displacement of vertical and horizontal. (b) The horizontal deformation. (c) The inclined deformation. (d) The curvature deformation.

\section{Conclusions}

Considering that the backfilling of the granular rock into the collapse pit can prevent the surface strata movement, this study introduced a method to determine the ultimate underground mining depth by considering the effect of granular rock and the range of surface caving. The method included numerical simulation, theoretical calculation, and surface displacement monitoring. The granular rock was simplified as the degraded rock mass in the finite element software FLAC ${ }^{3 \mathrm{D}}$, which increased the resistance of granular rock to the deformation of rock mass. The modified mechanical model for limiting equilibrium analysis of progressive hanging wall caving proposed in this work can more accurately determine the ultimate underground mining depth. However, the values of the indicators of surface deformation in the numerical simulation were below the critical value of dangerous movement in the condition of the results of theoretical calculation, which indicated that the method of numerical simulation can be a means of verification.

The surface displacement monitoring in this work can be used as a supplementary way to verify the implementation effect of the ultimate underground mining depth calculated 
in this work. The investigation results demonstrated that there were no tensile cracks and unexpected settlement between the collapse pit and the open-pit, which showed the scheme of coordinated rock backfilling can control the subsidence range and ensure the safe and efficient mining of the open-pit and underground synergetic mining. In brief, the ultimate underground mining depth calculated in this work can ensure the safety of the open-pit mining and prolong the service life of underground mining.

\section{Data Availability}

The data used to support the findings of this study are available from the corresponding author upon request.

\section{Conflicts of Interest}

The authors declare that they have no conflicts of interest.

\section{Authors' Contributions}

Rongxing $\mathrm{He}$ contributed to the formulation of the overarching research goals and aims. Rongxing $\mathrm{He}$ and Jing Zhang derived the equation of the modified mechanical model. Yang Liu contributed to the numerical simulation. Fengyu Ren and Rongxing He developed proposals for the backfilling scheme. Jing Zhang wrote the manuscript and Rongxing $\mathrm{He}$ checked the manuscript. Delin Song contributed to the collection of test data and references.

\section{Acknowledgments}

The support of the Key Program of National Natural Science Foundation of China (Grant no. 51534003) and the National Key Research and Development Program of China (Grant no. 2016YFC0801604) is gratefully acknowledged.

\section{References}

[1] H. Ding, G. Li, X. Dong, and Y. Lin, "Prediction of pillar stability for underground mines using the stochastic gradient boosting technique," IEEE Access, vol. 6, pp. 69253-69264, 2018.

[2] A. Zingano and A. Weiss, "Subsidence over room and pillar retreat mining in a low coal seam," International Journal of Mining Science and Technology, vol. 29, no. 1, pp. 51-57, 2019.

[3] S. Li, C. Fan, M. Luo, Z. Yang, T. Lan, and H. Zhang, "Structure and deformation measurements of shallow overburden during top coal caving longwall mining," International Journal of Mining Science and Technology, vol. 27, no. 6, pp. 1081-1085, 2017.

[4] X. Xu, F. He, X. Li, and W. He, "Research on mechanism and control of asymmetric deformation of gob side coal roadway with fully mechanized caving mining," Engineering Failure Analysis, vol. 120, Article ID 105097, 2021.

[5] H. Ding, S. Chen, S. Chang, G. Li, and L. Zhou, "Prediction of surface subsidence extension due to underground caving: a case study of Hemushan iron mine in China," Mathematical Problems in Engineering, vol. 2020, Article ID 5086049, 10 pages, 2020.
[6] M. Qian, X. Miao, and F. He, "Analysis of key block in the structure of voussoir beam in longwall mining," Journal of China Coal Society, vol. 31, no. 32, p. 191A, 1994.

[7] Z. Song, Utility Mine Pressure and Control, China University of Mining and Technology Press, Xuzhou, China, 1988, in Chinese.

[8] V. Palchik, "Formation of fractured zones in overburden due to longwall mining," Environmental Geology, vol. 44, no. 1, pp. 28-38, 2003.

[9] C. Mark, "Multiple-seam mining in the United States: background," in Proceedings: New Technology for Ground Control in Multiple Seam Mining, US Department of Health and Human Services, Public Health Service, Centers for Disease Control and Prevention, National Institute for Occupational Safety and Health, Pittsburgh, PA, USA, DHHS (NIOSH) Publication, no. 97-122, Pittsburgh, PA, USA, May 2007.

[10] M. Qian and H. Li, "The movement of overlying strata in longwall mining and its effect on ground pressure," Journal of China Coal Society, vol. 2, pp. 1-12, 1982.

[11] C. Liu, Research on Hazard Mechanism and Mieroseismie Warning Method for Gas Dynamie Disasters of Mining CoalRock, Dalian University of Technology, Dalian, China, 2011.

[12] M. G. Qian, X. X. Miao, and J. L. Xu, "Theoretical study of key stratum in ground control," Journal of China Coal Society, vol. 21, no. 3, pp. 225-230, 1996.

[13] M. G. Qian, X. B. Mao, and X. X. Miao, "Variation of loads on the overlying key strata above the workings," Journal of China Coal Society, vol. 23, no. 2, 1998.

[14] M. G. Qian, X. X. Miao, J. L. Xu, and X. B. Mao, Study of Key Strata Theory in Ground Control, China University of Mining and Technology, Xuzhou, China, 2003.

[15] Z.-X. Liu, T. Luo, X. Li, X.-b. Li, Z. Huai, and S.-f. Wang, "Construction of reasonable pillar group for undersea mining in metal mine," Transactions of Nonferrous Metals Society of China, vol. 28, no. 4, pp. 757-765, 2018.

[16] K. Xia, C. Chen, Y. Deng et al., "In situ monitoring and analysis of the mining-induced deep ground movement in a metal mine," International Journal of Rock Mechanics and Mining Sciences, vol. 109, pp. 32-51, 2018.

[17] E. T. Brown, Block Caving Geomechanics (International Caving Study I, 1997-2000), University of Queensland, JKMRC Monograph Series in Mining and Mineral Processing, Brisbane, Australia, 2003.

[18] E. Hoek, "Progressive caving induced by mining an inclined orebody," Transactions of the Institution of Mining and Metallurgy, vol. 83, pp. A133-A139, 1974.

[19] E. T. Brown and G. A. Ferguson, "Prediction of progressive hanging-wall caving, Gaths mine, Rhodesia," Transactions of the Institution of Mining and Metallurgy Section A-Mining Industry, vol. 88, pp. A92-A105, 1979.

[20] F. Ren, D. Zhang, J. Cao, M. Yu, and S. Li, "Study on the rock mass caving and surface subsidence mechanism based on an in situ geological investigation and numerical analysis," Mathematical Problems in Engineering, vol. 2018, Article ID 6054145, 18 pages, 2018.

[21] F. Y. Ren, Y. Liu, J. L. Cao et al., "Prediction of the caved rock zones' scope induced by caving mining method," PLoS One, vol. 13, no. 8, pp. 1-16, 2018.

[22] Y. Liu, F. Y. Ren, R. X. He et al., "Prediction of surface subsidence range based on the critical medium column's theory under ore drawing," Chinese Journal of Northeastern University (Natural Science), vol. 39, no. 3, pp. 416-420, 2018. 
[23] J. L. Cao, F. Y. Ren, H. X. Ding et al., "Study on surface rock movement control technology based on open-pit and underground synergetic mining," Chinese Journal of Metal Mine, vol. 1, pp. 37-43, 2020.

[24] J. Q. Zhu, "Primary analysis of geological hazard in the eastern area of Chengchao iron mine," Chinese Journal of Rock Mechanics and Engineering, vol. 18, no. 5, pp. 497-502, 1999.

[25] R. S. Xi and C. X. Chen, "Study of influence of discontinuities on rock movement and surface deformation in eastern area of Chengchao iron mine," Rock and Soil Mechanics, vol. 32, no. 2, pp. 532-537, 2011.

[26] G. W. Cheng, C. X. Cheng, and Q. Shen, "Mechanism of rock strata movement caused by underground mining in Chengchao iron mine," Rock and Soil Mechanics, vol. 35, no. 5, pp. 1421-1429, 2014.

[27] G. Cheng, C. Chen, T. Ma, H. Liu, and C. Tang, "A case study on the strata movement mechanism and surface deformation regulation in Chengchao underground iron mine," Rock Mechanics and Rock Engineering, vol. 50, no. 4, pp. 1011-1032, 2017.

[28] L. L. Chen, C. X. Chen, and K. Z. Xia, "Study on ground deformation around collapsed zone in Chengchao iron mine," Chinese Journal of Rock Mechanics and Engineering, vol. 37, no. 2, pp. 415-429, 2018.

[29] B. Unver and N. E. Yasitli, "Modelling of strata movement with a special reference to caving mechanism in thick seam coal mining," International Journal of Coal Geology, vol. 66, no. 4, pp. 227-252, 2006.

[30] Y. L. Fang, "UDEC numerical simulation research of mining overlying strata movement regulation," Applied Mechanics and Materials, vol. 448-453, pp. 3884-3887, 2013.

[31] G. Cheng, C. Chen, L. Li et al., "Numerical modelling of strata movement at footwall induced by underground mining," International Journal of Rock Mechanics and Mining Sciences, vol. 108, no. 6, pp. 142-156, 2018.

[32] Z. Wen, Y. Tan, Z. Han, and F. Meng, "Construction of timespace structure model of deep stope and stability analysis," Polish Journal of Environmental Studies, vol. 25, no. 6, pp. 2633-2639, 2016.

[33] J.-H. Wu, Y. Ohnishi, and S. Nishiyama, "Simulation of the mechanical behavior of inclined jointed rock masses during tunnel construction using Discontinuous Deformation Analysis (DDA)," International Journal of Rock Mechanics and Mining Sciences, vol. 41, no. 5, pp. 731-743, 2004.

[34] A. Vyazmensky, D. Stead, D. Elmo, and A. Moss, "Numerical analysis of block caving-induced instability in large open pit slopes: a finite element/discrete element approach," Rock Mechanics and Rock Engineering, vol. 43, no. 1, pp. 21-39, 2010.

[35] L. C. Li, C. A. Tang, X. D. Zhao, and M. Cai, "Block cavinginduced strata movement and associated surface subsidence: a numerical study based on a demonstration model," Bulletin of Engineering Geology and the Environment, vol. 73, no. 4, pp. 1165-1182, 2014.

[36] M. Singh and K. R. Seshagiri, "Empirical methods to estimate the strength of jointed rock masses," Engineering Geology, vol. 77, no. 1-2, pp. 127-137, 2005.

[37] E. Hoek and M. S. Diederichs, "Empirical estimation of rock mass modulus," International Journal of Rock Mechanics and Mining Sciences, vol. 43, no. 2, pp. 203-215, 2006.

[38] H. Sonmez, C. Gokceoglu, H. A. Nefeslioglu, and A. Kayabasi, "Estimation of rock modulus: for intact rocks with an artificial neural network and for rock masses with a new empirical equation," International Journal of Rock Mechanics and Mining Sciences, vol. 43, no. 2, pp. 224-235, 2006.

[39] E. Hoek and E. T. Brown, "Empirical strength criterion for rock masses," Journal of the Geotechnical Engineering Division, vol. 106, no. 9, pp. 1013-1035, 1980.

[40] E. Hoek and E. T. Brown, "Practical estimates of rock mass strength," International Journal of Rock Mechanics and Mining Sciences, vol. 34, no. 8, pp. 1165-1186, 1997.

[41] E. Hoek and E. T. Brown, "The Hoek-Brown failure criterion and GSI-2018 edition," Journal of Rock Mechanics and Geotechnical Engineering, vol. 11, no. 3, pp. 445-463, 2019.

[42] H. Ozturk and M. Altinpinar, "The estimation of uniaxial compressive strength conversion factor of trona and interbeds from point load tests and numerical modeling," Journal of African Earth Sciences, vol. 131, pp. 71-79, 2017.

[43] O. Mohr, "Welche umstande bedingen die elastizitatsgrenze und den bruch eines materials," Zeitschrift des Vereins Deutscher Ingenieure, vol. 44, pp. 1524-1530, 1900.

[44] Z. H. Zhou, K. P. Hou, and F. Y. Ren, "Stability analysis of large-scale mined-out area and its control methods in Paomaping lead-zinc deposit," Journal of Mining \& Safety Engineering, vol. 30, no. 6, pp. 863-867, 2011.

[45] G. Q. He, L. Yang, and G. D. Ling, Mining Subsidence Theory, China University of Mining \& Technology Publisher, Xuzhou, China, 1991.

[46] H. G. Biady and E. T. Brown, Rock Mechanics for Underground Mining, George Allen \&Unwin, London, UK, 1985.

[47] M. Budhu, Soil Mechanics and Foundations, Jonn Wiley \& Sons, Inc., New York, NY, USA, 2010.

[48] Q. Sun, J. Zhang, and Q. Zhang, "A case study of mininginduced impacts on the stability of multi-tunnels with the backfill mining method and controlling strategies," Environmental Earth Sciences, vol. 77, pp. 234-247, 2018.

[49] M. Li, J. Zhang, K. Sun, Z. Wu, and N. Zhou, "Reducing surface subsidence risk using solid waste backfill technique: a case study under buildings," Polish Journal of Environmental Studies, vol. 28, no. 5, pp. 3333-3341, 2019.

[50] Q. Zhang, J. Zhang, Z. Wu, and Y. Chen, "Overview of solid backfilling technology based on coal-waste underground separation in China," Sustainability, vol. 11, no. 7, pp. 2118-2138, 2019. 